\title{
Mount Athos: Restoration of an Almost Extinct Type of 18th-19th C. UNESCO Masonry OX Stable
}

\author{
Styliani Papatzani $1, * \mathbb{*}$, Nikolaos Pnevmatikos ${ }^{2} \oplus$, Konstantinos Dimitroulias ${ }^{3}$, Georgios Michail ${ }^{1}$, \\ Georgios Sapiridis ${ }^{4}$ and Vasilakis Flentzouris ${ }^{4}$ \\ 1 Directorate for the Restoration of Byzantine and Post-Byzantine Monuments, Hellenic Ministry of Culture \\ and Sports, 8-10 Tzireon Street, 11742 Athens, Greece; yorgosmic@gmail.com \\ 2 Department of Civil Engineering, School of Engineering, University of West Attica, 250 P. Ralli \& Thivon, \\ 12244 Egaleo, Greece; pnevma@uniwa.gr \\ 3 Directorate of Studies and Conduction of Technical Works in Museums and Cultural Buildings, \\ Hellenic Ministry of Culture and Sports, 12 Karytsi Square, 10561 Athens, Greece; kdimitroulias@culture.gr \\ 4 Proentasi-George D. Sapiridis \& Associates-Design and Construction Company, 4 Skopou Street, \\ 54636 Thessaloniki, Greece; sapiridis@gmail.com (G.S.); vflentzo@yahoo.gr (V.F.) \\ * Correspondence: spapatzani@gmail.com
}

check for

updates

Citation: Papatzani, S.;

Pnevmatikos, N.; Dimitroulias, K.;

Michail, G.; Sapiridis, G.;

Flentzouris, V. Mount Athos:

Restoration of an Almost Extinct Type of 18th-19th C. UNESCO Masonry OX Stable. Heritage 2021, 4, 1284-1303. https://doi.org/10.3390/

heritage 4030070

Academic Editor: Vagelis Plevris

Received: 2 June 2021

Accepted: 7 July 2021

Published: 15 July 2021

Publisher's Note: MDPI stays neutral with regard to jurisdictional claims in published maps and institutional affiliations.

Copyright: (c) 2021 by the authors. Licensee MDPI, Basel, Switzerland. This article is an open access article distributed under the terms and conditions of the Creative Commons Attribution (CC BY) license (https:/ / creativecommons.org/licenses/by/ $4.0 /)$.

\begin{abstract}
The present paper serves the purpose of presenting an extinct type of 18th-19th century masonry building, that of an ox-stable, situated in one of Europe's most secluded areas: The Holy Monastery of Pantokrator in Mount Athos Peninsula. Architectural drawings and surveying plots of its current state can serve as a record and reference of this UNESCO site for scholars. Adding to that, an elaborated proposal for the reuse of the building is presented together with technical drawings, which were approved by Greece's Central Archeological Council. The masonry rectangular building is founded on natural rock with masonry pillar footings of different heights. Hence, the elevation irregularity and the different elevations of the footings of the structure present an additional challenge for the structural analysis. Structural analysis with a finite element (FE) model of the restored structure was executed with SAP2000 software. Performing lateral force and response spectrum analyses, stresses and deformations at critical points of the structure were calculated. Comparing a set of simplifying structural checks with the elastic FE analysis performed, it was concluded that the proposed design is effective in improving the earthquake performance of the structure.
\end{abstract}

Keywords: UNESCO; Mount Athos; masonry ox-stable; Central Archeological Council; finite element analysis; SAP2000

\section{Introduction}

The United Nations Educational, Scientific and Cultural Organization world Heritage Sites are places of importance to cultural or natural heritage as described in the UNESCO World Heritage Convention, established in 1972. It has been discussed that a number of key dates led to the convention in the aftermath of WWII [1]. Greece ratified the convention in 1981.

As of today, Greece has included 18 monuments and sites in the list, 16 of which are sites, and two are listed for both cultural and natural importance. Greece has 14 sites as well on the tentative list and they may be considered for nomination in the future:

1. Temple of Apollo Epicurius at Bassae 1986;

2. Archeological site of Delphi 1987;

3. Acropolis, Athens 1987;

4. Mount Athos 1988;

5. Meteora 1988;

6. Paleochristian and Byzantine monuments of Thessaloniki 1988;

7. Sanctuary of Asklepios at Epidaurus 1988; 
8. Medieval City of Rhodes 1988;

9. Archeological site of Mystras 1989;

10. Archeological site of Olympia 1989;

11. Delos 1990;

12. Monasteries of Daphni, Hosios Loukas and Nea Moni of Chios 1990;

13. Pythagoreion and Heraion of Samos 1992;

14. Archaeological Site of Aigai (modern name Vergina) 1996;

15. Archaeological site of Mycenae and Tiryns 1999;

16. The Historic Centre (Chorá) with the Monastery of Saint-John the Theologian and the Cave of the Apocalypse on the Island of Pátmos 1999;

17. Old Town of Corfu 2007;

18. Archaeological Site of Philippi 2016.

The Holy Monastery of Pantokrator is a historic monument situated in one of Europe's most secluded areas—on Athos peninsula (Figure 1), which is registered on the UNESCO World Heritage List since 1988, as shown above. The peninsula offers limited access to male visitors only; therefore, it is significant to present parts of the monuments in a scholarly manner. Athos Peninsula has a perimeter of fifty kilometers, hosts twenty Byzantine monastery complexes, and has a population of over 2000 monks [2]. The entire Pantokratoros monastery complex, comprises, therefore, a listed monument. The ox stable (locally called "Vourdounario") of the monastery is a rare, representative specimen of an extinct type of building, as most of the monasteries' stable buildings have changed use/function, or have been demolished due to the replacement of ox-driven agricultural equipment by machines for various field works.

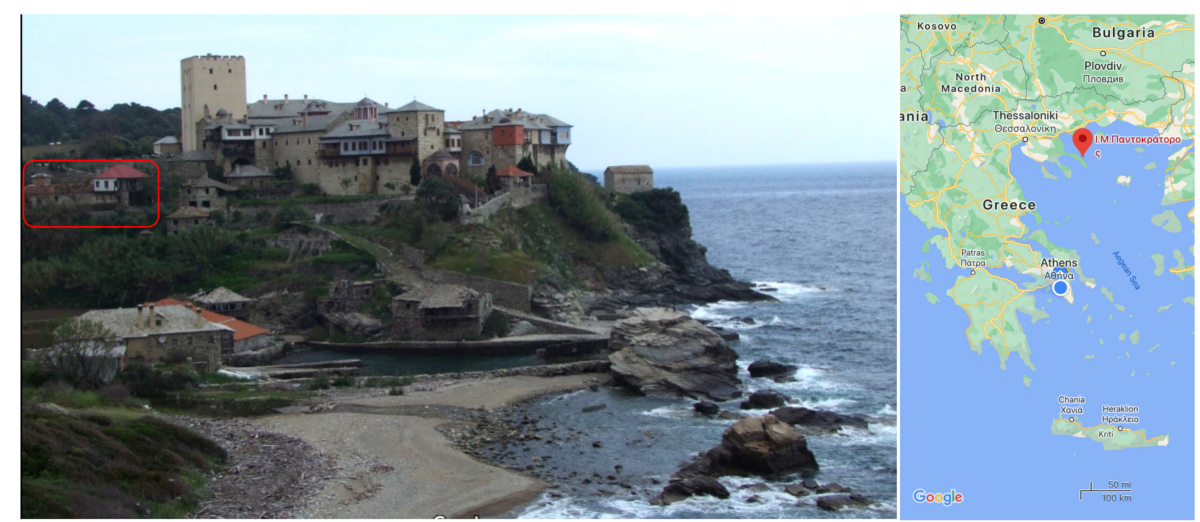

Figure 1. The vourdounario and its location with respect to the monastery complex and Athos Peninsula (Google maps).

Despite the damage the monument has suffered, it still preserves its authentic character and the main elements of its typology and function. Restoring and conserving such a building type contributes to the survival of a rare example of a stable, representative of the agrarian culture of the region, while at the same time promoting the cultural heritage of the peninsula and the monastery itself.

The Monastery of Pantokrator was founded in the second half of the 14th c., a period of trouble for the Byzantine Empire which was facing invasions, although the monastery tradition refers to the period of Alexius I Comnenos (1081-1117); two byzantine officials and brothers are mentioned as founders, namely Alexius and Ioannes, who possessed large estates in eastern Macedonia, Greece; some of them were granted to the monastery. In the year of 1392, a fire induced significant damages to the monastery complex and restoration works started soon after. In 1423-4 Mount Athos paid tribute (surrendered in a way) to the Ottomans (Murat II), while during the 16th c. the monastery was supported economically by orthodox local rulers of Danube region. In the period from the middle of the 17th until the middle of the 18th c., the monastic community was faced with pirate invasions from 
which it started recovering decades later. During the Greek Revolution (1821) [3], the monasteries of Athos supported the Greek Revolution.

The date of construction of the ox stable is not known, but it presents a typical form of such a type of building in Mount Athos during the 18th and 19th centuries. In an engraved inscription, which is preserved on a stone on the staircase, the year 1863 is quoted.

To date, the earliest known depiction of the structure is given in an 1871 photograph cited in Pilgrim's guide of Paschalides [4].

Given the age of the complex and the fact that it comprises a UNESCO site, any restoration proposal must be analyzed at and discussed through Greece's Central Archaeological Council. The Central Archaeological Council and Museums Council (CAC) also known by the Greek abbreviation KAS (KA $\Sigma$ ), is the supreme advisory body for all that concerns the protection of cultural heritage in Greece.

As an effect, a significant part of the current paper was submitted to and accepted by CAC and the Minister of Culture, and therefore can serve as a reference for scientists who are interested in these types of extinct structures and to engineers who are interested not only in the rehabilitation of monuments but also in passing successfully such an administrative procedure.

The current paper is divided into the following sections:

1. The Central Archaeological Council of Greece (CAC);

2. The presentation of the current condition of the monument through surveying plots and architectural drawings;

3. The pathology of the structure through selected photographs;

4. The proposal for the restoration of the monument, through architectural drawings, which were submitted to and approved by the Central Archeological Council of Greece and relevant discussion;

5. The structural analysis of the monument, and discussion stemming from the comparison of the analysis of the entire structure and structural checks, which can replace the analysis in some cases;

6. Conclusions.

To the best knowledge of the authors, this is the first time that a listed monument of this type has been recorded for future generations and presented to scientists and the general public. Moreover, the methodology followed for the verification of such monuments through the Central Archeological Council of Greece is also presented, and a comparison of simplifying structural checks and structural analysis results is also provided.

\section{Central Archaeological Council of Greece (CAC)}

The Council is regulated at present by Law 3028/2002, but its history dates back to 1834, when the first committee for the protection of monuments was established, called the Central Committee of the Greek Archaeological Service by Law 10/22 May 1834. Its composition was defined by Royal decree 16/28 November 1936 and its first session took place on 13 May 1837.

The Central committee was replaced by the Archeological committee by Law BXM $\Sigma \mathrm{T} / 1899$ when it was given broader powers and authority.

It was later renamed again to the Archeological Council in 1910 according to Law $\Gamma \Psi \Lambda 3730 / 1910$. It should be noted that laws published in the 1800s and 1900s were numbered with Greek letters followed by numbers, and lastly, the year the law was published.

Its current name finally dates back to 1977, when the presidential decree 890/4 November 1977 was issued regulating its functions.

The CAC is composed of 17 members selected among scientists, educators, artists and archeological researchers, with the Secretary General of the Ministry of Culture acting as the head of the council. Members include five archeologists, the director of regional or special regional services of the Ministry of Culture, seven university professors or research associates, one architect representing the Ministry of Environment and Energy, the Legal Counselor of the State to the Minister of Culture, the Director-General of Antiquities, and 
the Director-General of Restoration of Monuments and Technical Works of the Ministry of Culture, although the last two were replaced by the latest Law amendments by persons with similar qualifications.

The CAC gives advisory opinion to the Minister of Culture related to: the protection of cultural heritage, the management and restoration of monuments and sites, the designation and establishment of archaeological and historical sites and protection zones, the issuance of permits for the demolition of monuments, the compulsory expropriation or direct purchase or exchange of immovable monuments, the detachment of elements from monuments of outstanding importance, the export loan and the exchange of artifacts, the recognition of private collections and the acquisition of state collections, the protection of monuments entered on the UNESCO World Heritage List, and monuments, archaeological or historical sites of outstanding importance.

\section{Description of the Monument}

The structure consists of two connected blocks (structurally dependent as they share a wall, and the timber diaphragm of its block originally was supported on that wall, too); a single-storey rectangular masonry block, which served as an ox stable "vourdounario"; a two-storey masonry building, which served as a workmen's house and hence combined two distinct uses, respectively (Figure 2).

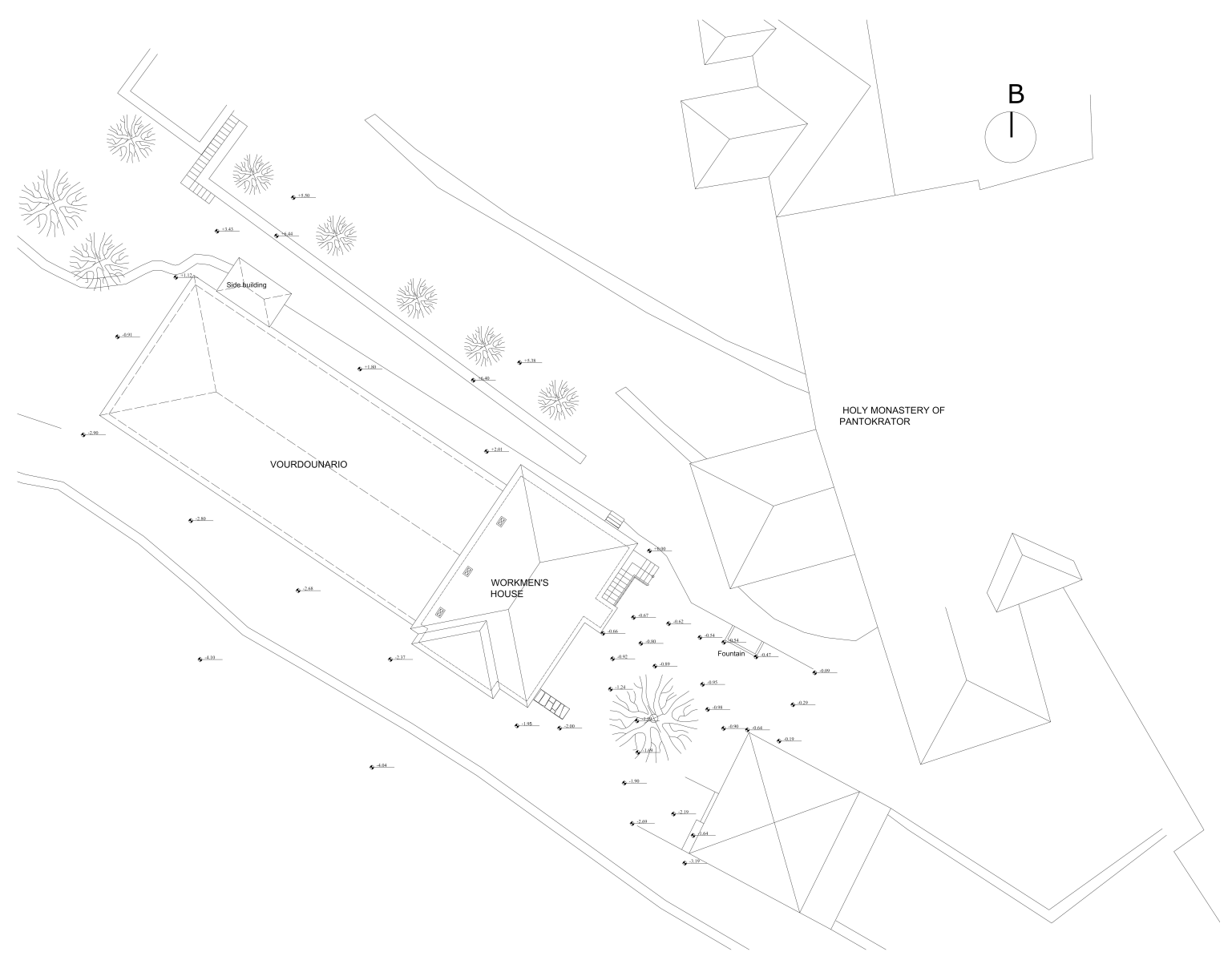

Figure 2. Surveying plot of the monument (Vourdounario \& Workmen's house).

The building is elongated with a rectangular floor plan, and it is constructed by single leaf stone masonry of $103 \mathrm{~cm}$ thickness in the basement (and $73 \mathrm{~cm}$ wall thickness in the first floor). Timber ties can be identified in random areas. Furthermore, stone pillars of $60 \mathrm{~cm} \times 60 \mathrm{~cm}$ cross section and 8 timber internal columns $(18 \mathrm{~cm} \times 18 \mathrm{~cm}$ cross section) can be distinguished. The roof is covered by a pitch timber roof with a hip end, covered by 
metal sheet. The entire structure is founded on natural rock with a steep inclination. Hence, a significant foundation height irregularity is prominent, and although the main volume of the structure in the south shows a two-floor structure, in the north it is a semi-basement (Figure 3). The roof consists of timber triangular trusses spaced at $1.40 \mathrm{~m}$. All floors were made of timber, forming diaphragms at each respective level.

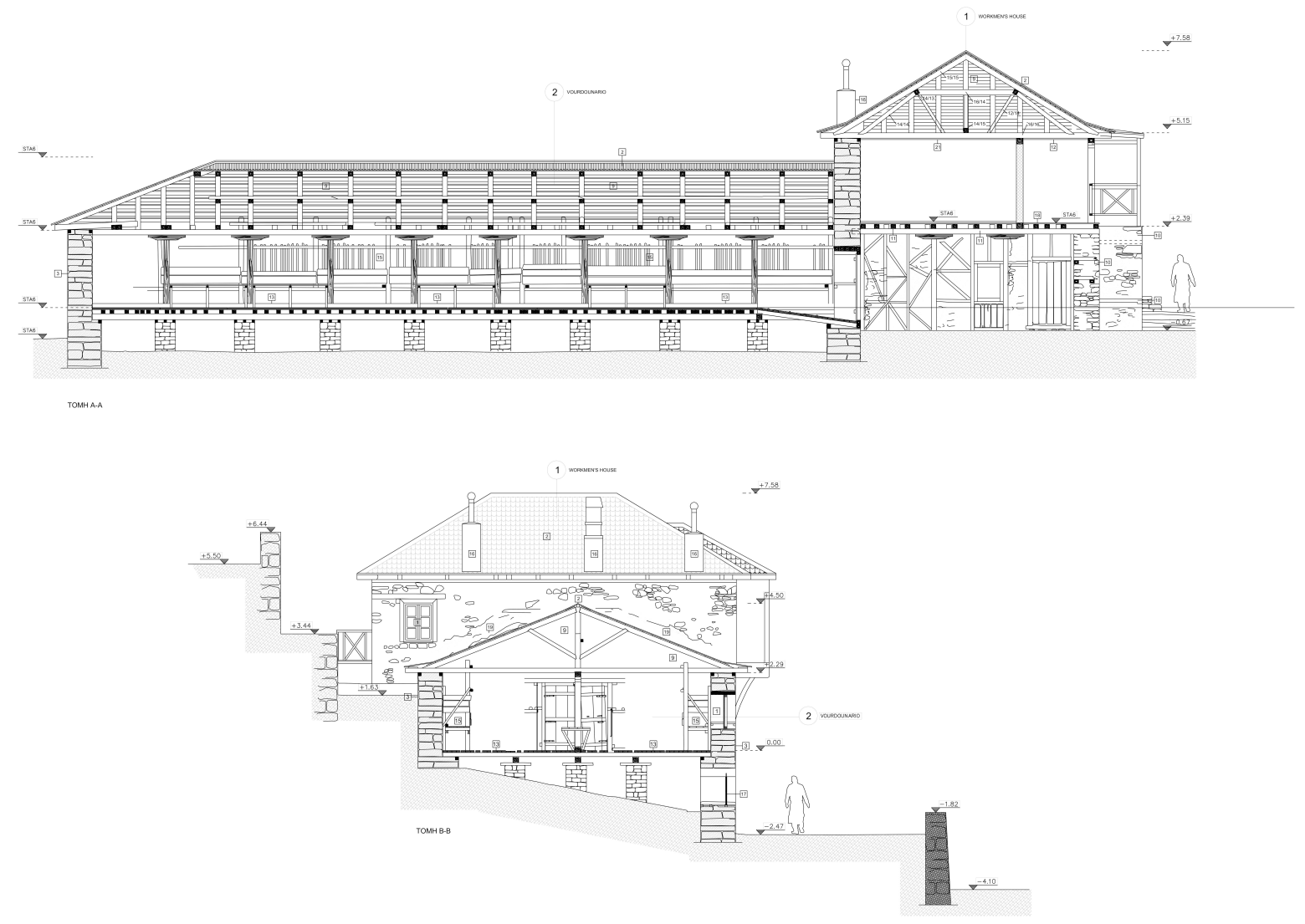

Figure 3. Sections of the monument (Vourdounario \& Workmen's house).

The western part of the building (Figure 4) has a floor plan of $9.30 \mathrm{~m} \times 22.60 \mathrm{~m}$ and a height of $5.70 \mathrm{~m}$. It hosted the stall and occupied the western part of the monastery complex. It is a ground floor building with a basement, which, due to the steep slope of the ground, appears as a ground floor on the south side, as shown by the section drawings (Figure 3) and side view drawings (Figure 5). Cover is provided by a pitch roof with a hip end (Figure 6). Despite its deterioration, the monument retains its originality and the typical elements of its function. In fact, the ground floor plan drawing shows the timber flooring, denoted by numbers 13 and 18, the timber roof, animal feeders (denoted by number 15), benches, etc. Structural elements of significant cross sections are present, as expected, since the structure was designed to withstand significant live loads imposed by oxen. It has been reported that the average weight of an ox fluctuates seasonally, but can be estimated at around $300 \mathrm{~kg}$ [5]. This stable could have provided home to a population of 80 oxen, therefore, $24,000 \mathrm{~kg}$, a significant weight to be supported by the structure.

The geometry of the building openings varies according to the use of each space. The openings (mainly windows) in the stable's basement are typically arched, formed with bricks (Figure 4, Figure 5-top, and Figure 6). The openings in the stable are closed with wooden covers on the ground floor and with simple window grates in the basement (Figure 4). 


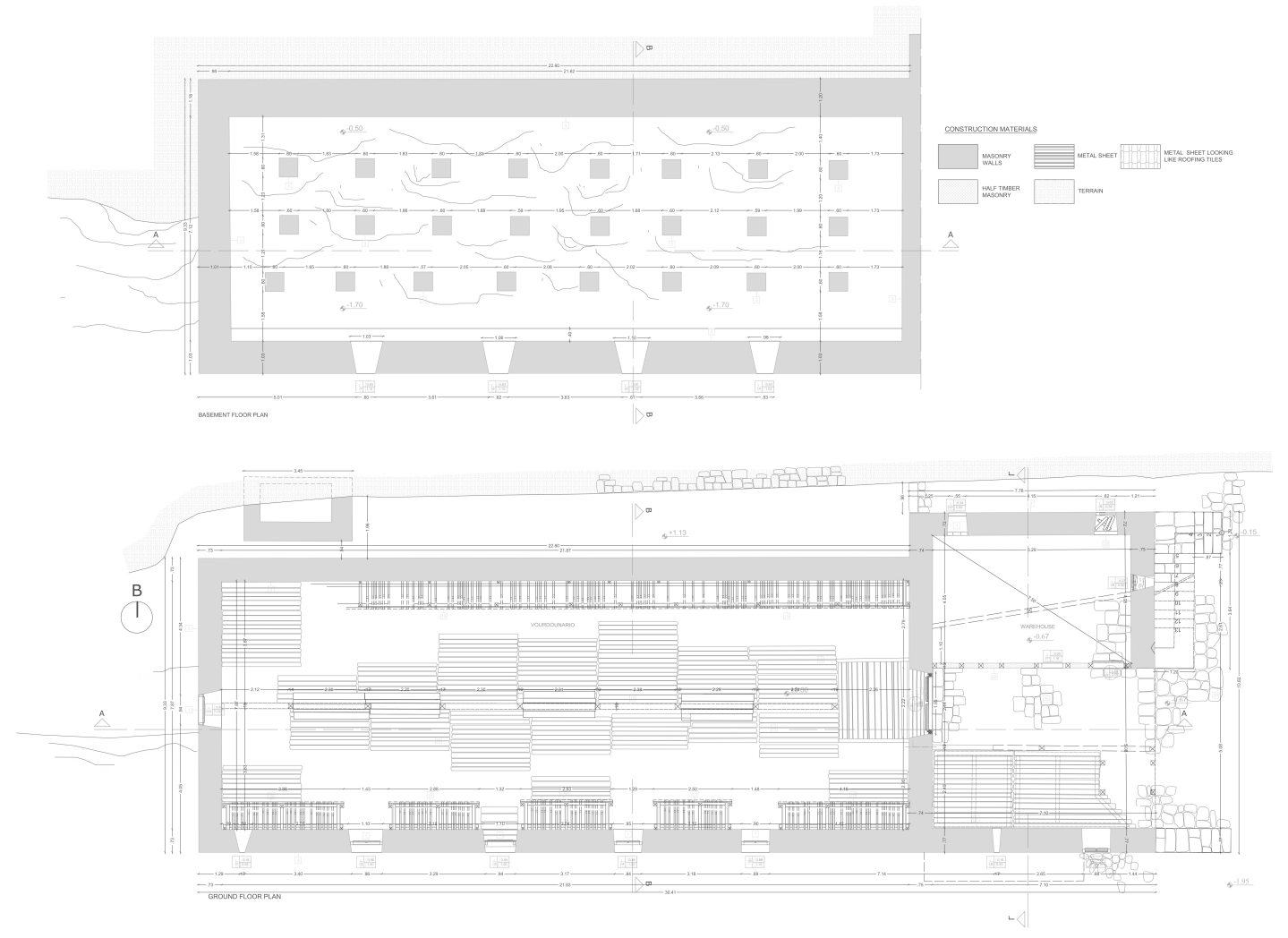

Figure 4. Basement and ground floor plan of the monument (Vourdounario \& Workmen's house).
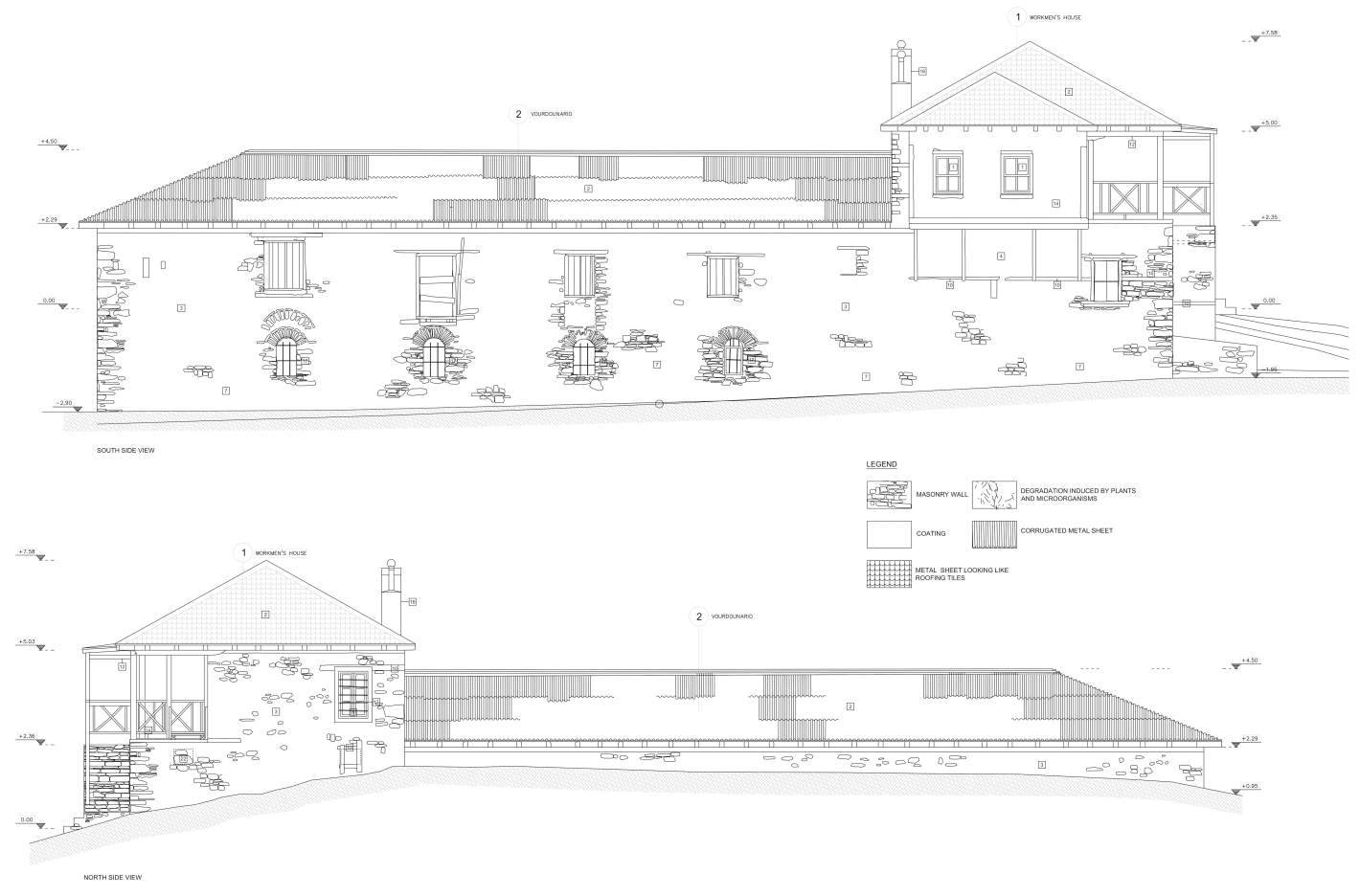

Figure 5. Side views of the monument (Vourdounario \& Workmen's house). 
(a)

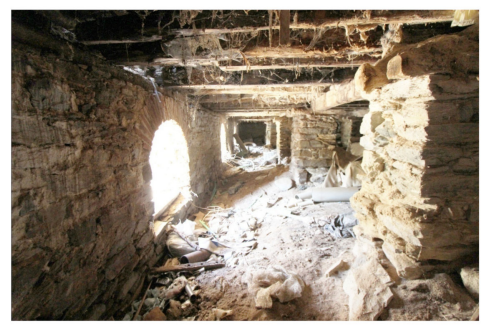

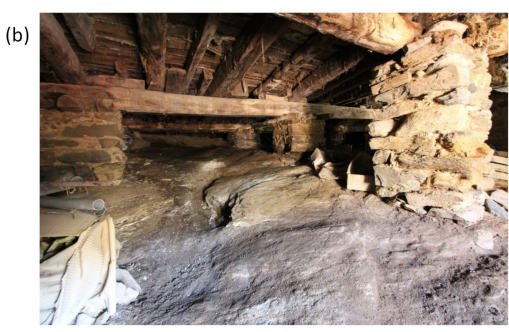
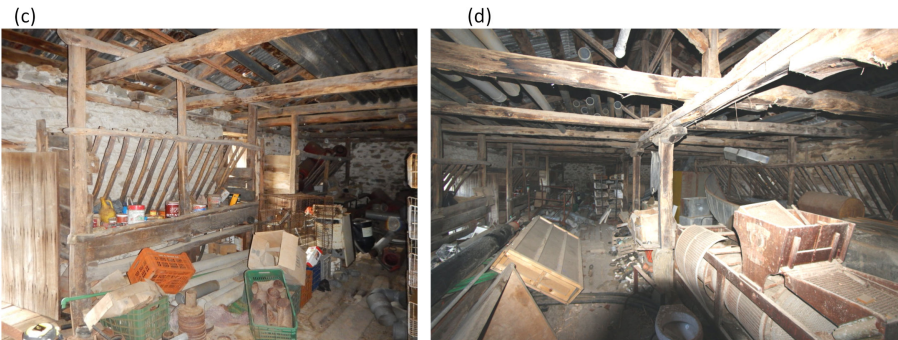

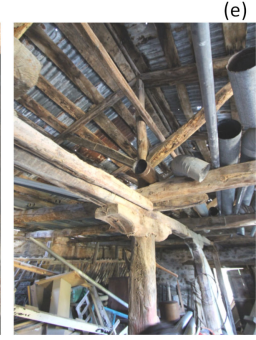

Figure 6. The vourdounario's interiors; (a) arched openings at the foundation level; (b) masonry pillar foundation on natural rock; (c) ground floor interiors-ox feeders; (d) timber columns, floors and roof beams and frames; (e) timber central column and roof frames.

The eastern part has a floor plan of $10.80 \mathrm{~m} \times 7.80 \mathrm{~m}$ and a height of 7.40 (Figure 4). The wall thickness reaches $75 \mathrm{~cm}$ on average. It houses the workmen's house and forms the eastern part of the complex (Figures 4, 5 and 7, Figures 8 and 9). It is a two-floor construction with a four-sided roof. In the northeast part of the ground floor there is a room, while in the southern part of the building a cobblestone semi-open area provides access to the stable. The access to the first floor was through an arched staircase on the east side of the building, as well as by a small timber bridge to the north, leading to a covered balcony that occupies the entire east side of the level. This balcony gives access to the three rooms of the floor. The two side rooms housed dormitories, while the middle one hosted the kitchen. The room on the south side protrudes outward from the main walls of the building, forming a "sahnisi" supported by timber struts. Sahnisi is a sort of bay window made of timber typically found in Greece, the Balkans, and Turkey. Traditionally, photos showing the interiors of the workmen's house are not taken, out of respect for the monks, but the exteriors are shown in Figures $9 \mathrm{c}$ and 10b.

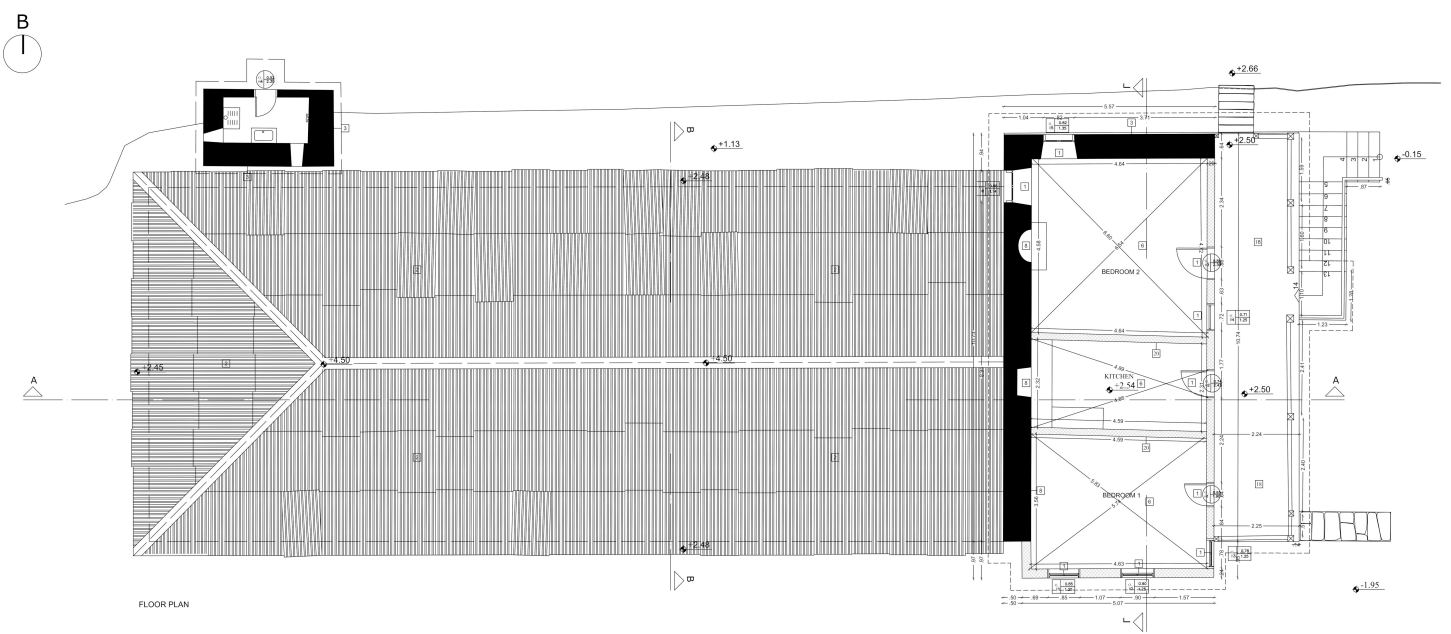

Figure 7. The roof of the Vourdounario and first floor plan of the workmen's house. 


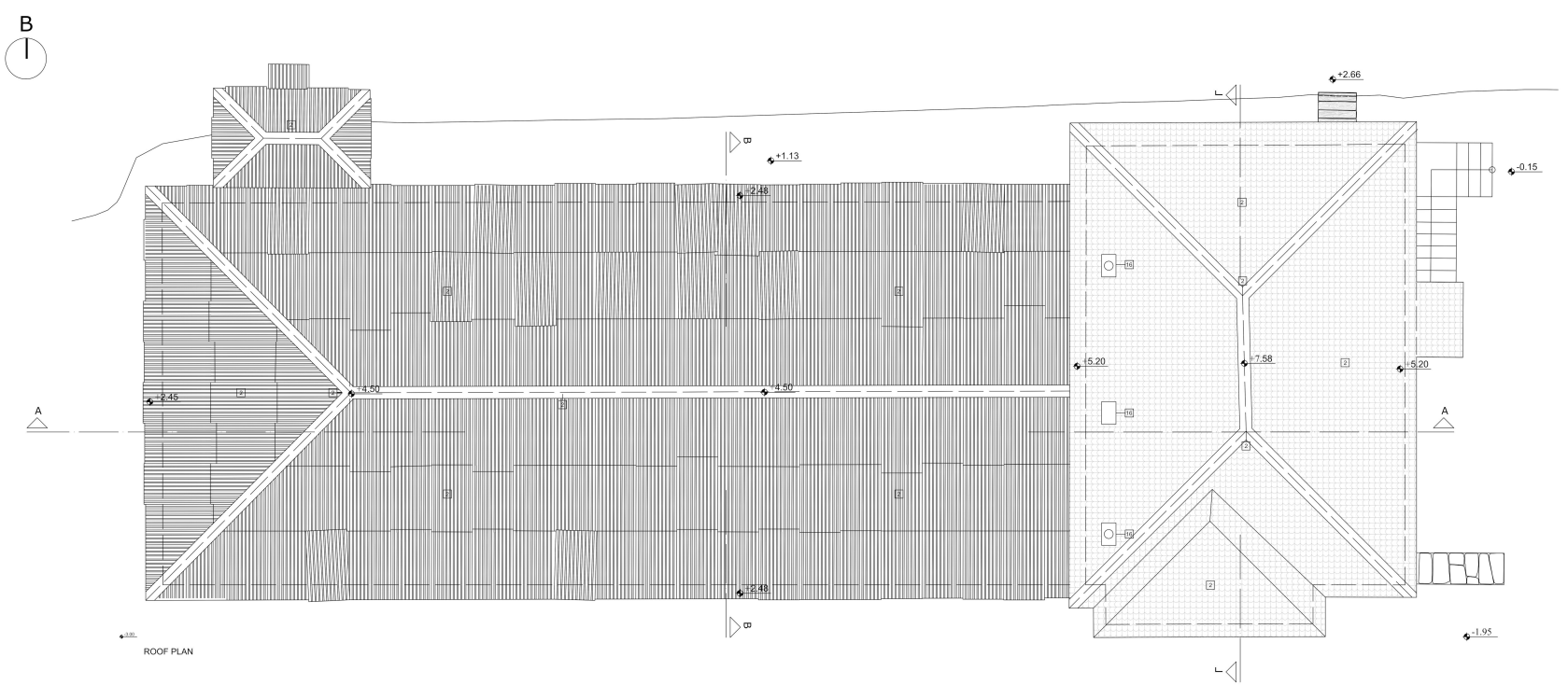

Figure 8. Roof plan of the monument (Vourdounario \& Workmen's house).

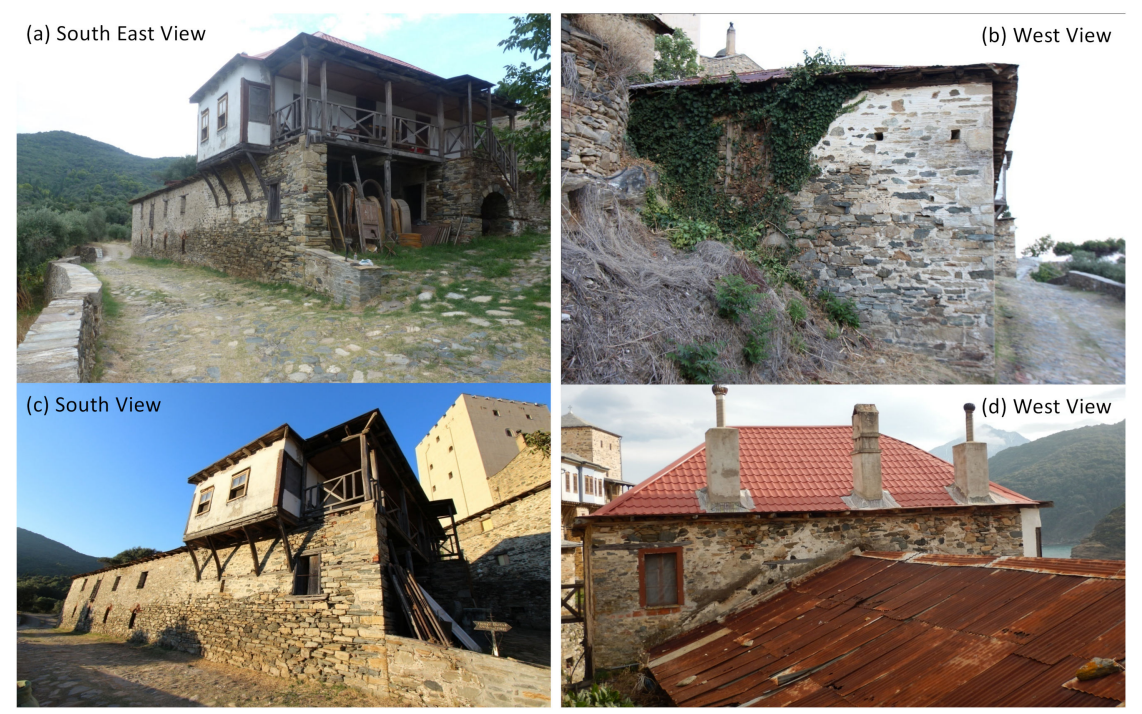

Figure 9. Recent photographs of different views of the structure. (a) South east view shows the two-floor workmen's house and the south side of the "vourdounario" stable. (b) West view shows the west side of the "vourdounario" stable. (c) South view shows the south side of the single-floor "vourdounario" and the two-floor workman's house towards the east and (d) West view shows the traces where the old roof used to be in contact with the wall of the workmen's house.

After careful observation, no significant changes can be traced to the form or structure of the building due to past building programs. Building phases resulted mostly from repairs, after damages that occurred during its long history.

One of the largest interventions that was implemented was the replacement of the stone slabs as a roof cover with metal sheets.

On the southern elevation, a number of past building interventions can be observed (Figure 11). The central part above the arched windows has been repointed at a later time. The top part of the northern corner of the southern elevation has been reconstructed, probably after a local collapse. This can be concluded due to the differentiation of the cornerstones used along with different morphological elements, such as the tall embrasure opening and the rectangular beam holes, the lintel of the window on the first-floor level which is in a higher level than the rest, the discharging arch below the said window, and finally the use of a different repointing finish technique. The same technique can be found 
below the sahnisi (bay window), where another embrasure opening can be seen. A sealed embrasure opening can be found near the base of the sahnisi. Another intervention is the transformation of a door to a window; this window is located east of the door of the southern elevation.
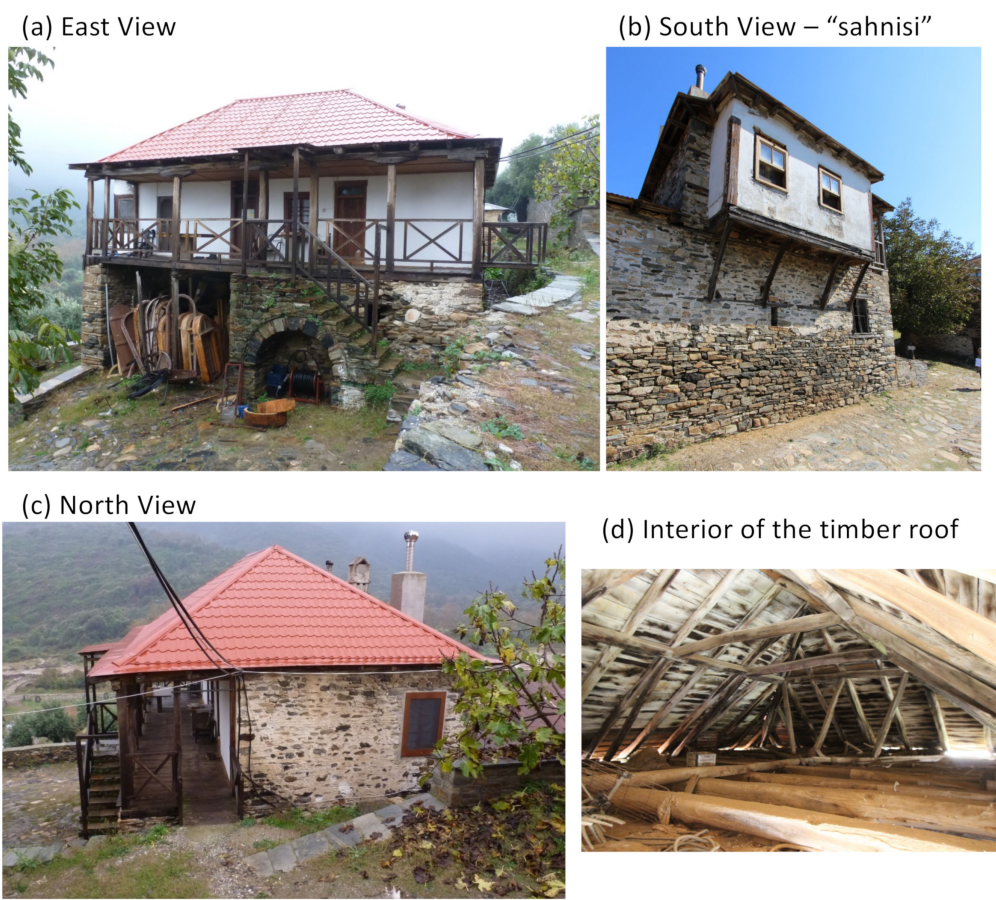

(d) Interior of the timber roof

Figure 10. "Workmen's house"; (a) east view; (b) south view with the "sahnisi"; (c) north view; (d) interior of the timber roof.

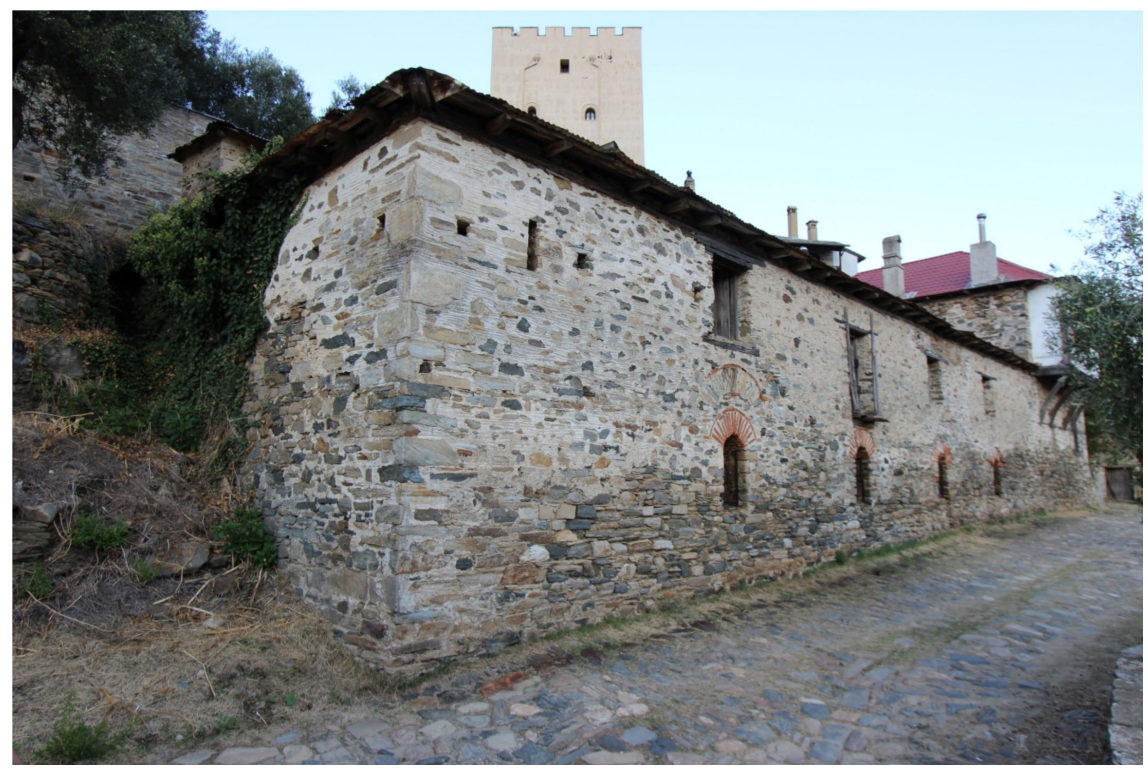

Figure 11. Southern elevation of the vourdounario showing traces of past interventions.

In the workmen's house, the interventions are limited to the concrete covering of the first-level floor, the replacement of all the windows (excluding the one next to the sahnisi), the removal of the fireplace of the southern chamber, the replacement of the wooden railing of the balcony, and the use of plywood as top cover for the balcony of the northern chamber. 


\section{Pathology of the Monument}

The stable is currently in a poor condition, with deterioration attributed to (a) waterrelated damage; (b) biological-chemical attacks (insects, vegetation and salts); (c) lack of maintenance. In brief the following can be observed:

1. Moisture has caused severe decay of all timber elements (Figure 12A,B,D-G), wooden parts and equipment (Figure 12C). In greater detail, the timber struts have severely deteriorated (Figure 12A). Furthermore, the timber floors and roofs (Figure 12B,E,F) have been additionally attacked by wood-eating insects (Figure 12G). This is observed in both the "vourdounario" and the workmen's house. The timber beams of the sahnisi have also deteriorated (Figure 12D). The same is valid for the window panes (Figure 12H).

2. Masonry walls (Figure 12I,J) and pillar footings present losses of stone material and bedding mortar. A significant percentage of the jointing material has been washed out in the exterior part of the walls, while extensive vegetation is present in a number of locations (Figure 12K).

3. The brick elements, which form the arched openings, present extensive peeling (Figure 12L).

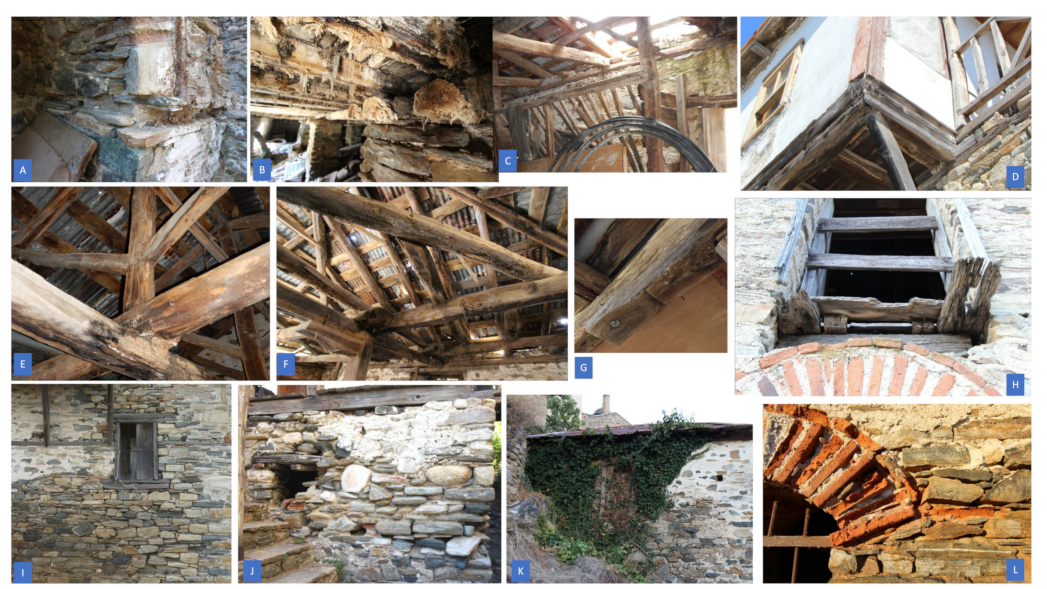

Figure 12. Characteristic pathology of the monument (Vourdounario \& Workmen's house); (A) decay of timber struts, (B) decay of timber floors, (C) decay of timber roof, wooden elements (animal feeders) and local loss of metal sheet, (D) deterioration of timber beams of sahnisi, (E,F) deterioration of timber roof trusses, $(\mathbf{G})$ attack of wood-eating insects, $(\mathbf{H})$ deterioration of wooden window panes, (I,J) loss of stone material, jointing material and bedding mortar in masonry walls, (K) vegetation growth on walls and (L) peeling of brick elements.

Water ingress is aggravated by the current lack of horizontal diaphragms, the local loss of metal sheet (Figure 12C), and the fact that a significant percentage of the jointing material has been washed out in certain areas. Weak connections between the walls were not observed and seismically induced cracks were not present on the masonry walls. Furthermore, the beams of the timber roof do not seem to have sustained significant deformation.

\section{Proposal and Discussion for the Restoration of the Monument}

The restoration works take into consideration The Venice Charter [6] for the conservation and restoration of monuments and sites, along with all contemporary theories and charters on the conservation and restoration of monuments.

The structure will be restored and maintained as a typical ox-stable "museum on its own right". It will be rendered visitable and the workmen's house will host necessary facilities, as discussed below. The design proposal includes repairs and the replacement of timber structural elements and the strengthening of masonry walls by deep repointing and grouting. Work in the interior is kept at a minimum. The restoration of the stable is designed with minimum interventions while performing maintenance to its operational 
equipment. The roof is to be restored to its original form along with the repairing/replacing of timber members. The roof of the workmen's house is to be restored to its current form.

The proposal is based on maintaining the morphology of the structure while restoring damaged and decayed elements and on reconstructing damaged and lost architectural building elements, while at the same time improving badly implemented past interventions.

The architectural proposal introduces basic building facilities, like rest rooms (in the workmen's house) which are necessary for its new function, and focuses on promoting the building's historical, architectural and aesthetical values so as to house a museum for the history of the Monastery of Pantokrator and Mount Athos.

The structural proposal is based on improving and strengthening the structure to withstand future seismic activity.

The restoration works include:

1. Reconstruction of masonry in the openings of the building, where material has locally collapsed;

2. Structural strengthening of masonry elements and application of new deep repointing and grouting in areas where the authentic mortar has been washed out, particularly in a number of masonry pillars of the basement (marked with numbers 12 and 13 in Figure 13, top);

3. Conservation of the original grouting in the building's interior;

4. Conservation of the timber/wooden elements of the building and replacing them in cases of irrecoverable damage (pillars, floors, walls, frameworks, morphological elements, balcony and staircase banisters);

5. Reconstruction of the wooden windows and doors and of the metal railings in the openings in the basement (Figure 14);

6. Reconstruction of the roof of the stable, using stone slabs as top cover (Figure 15);

7. Construction of sanitary facilities and ceramic tile covering;

8. Construction of a cobblestone path surrounding the monument;

9. Construction of a drainage system.

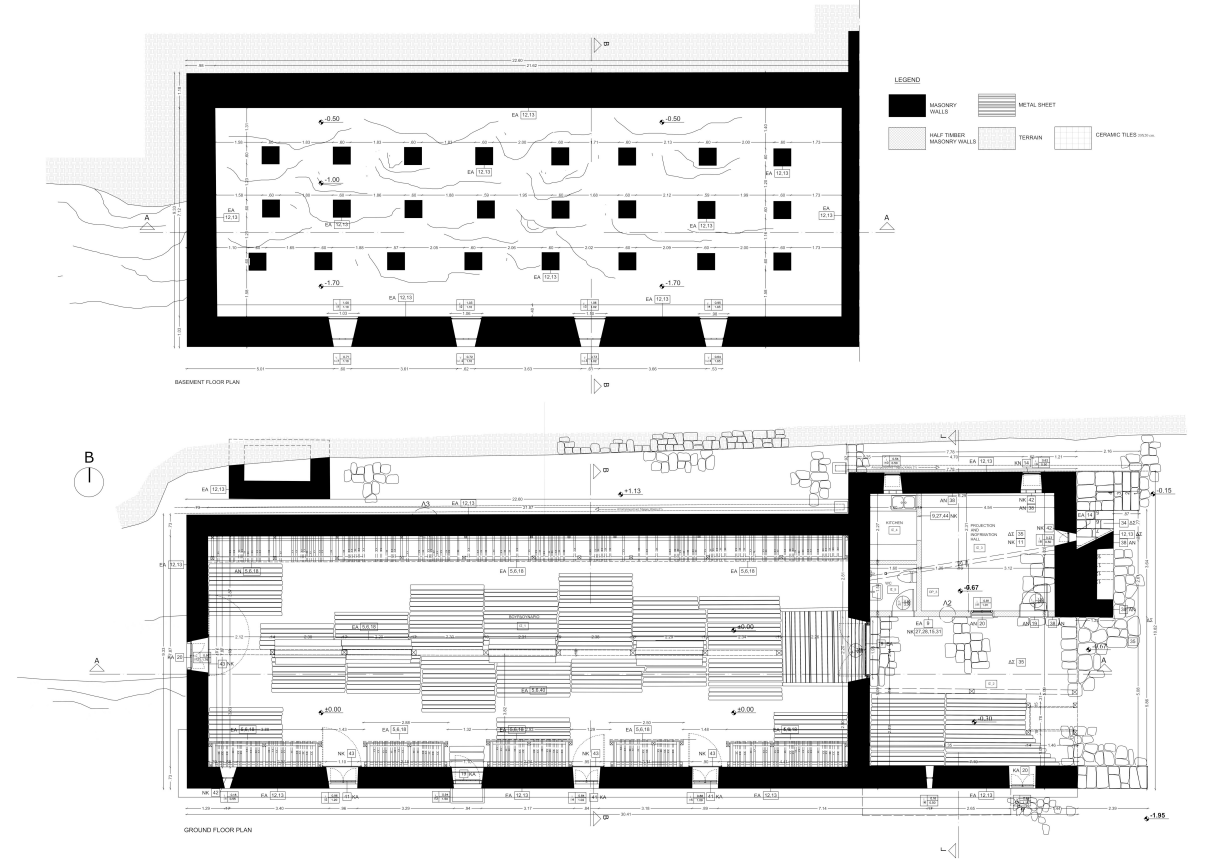

Figure 13. Basement and ground floor plan of the proposal for the restoration of the monument (Vourdounario \& Workmen's house). 


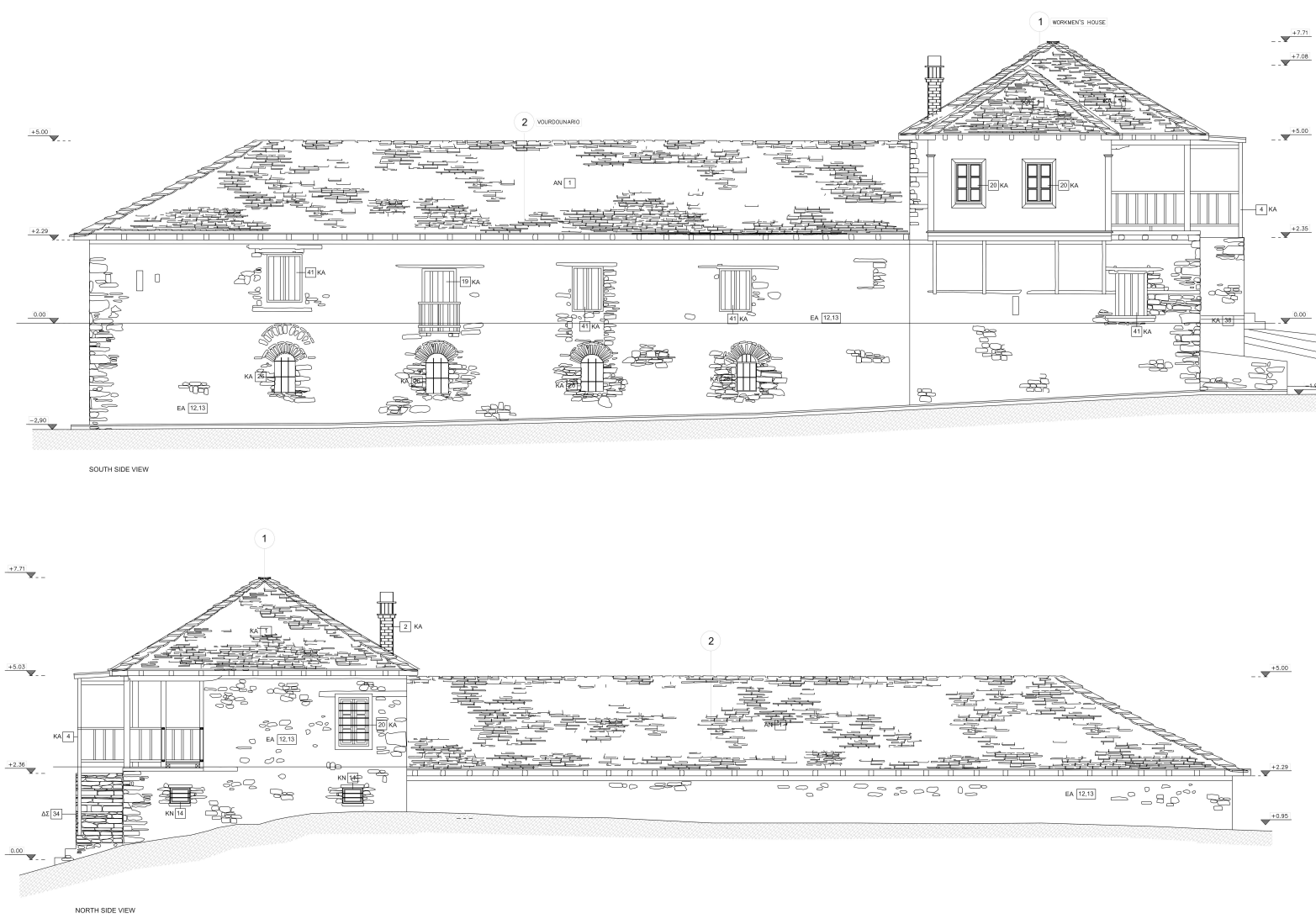

Figure 14. Side views of the proposal for the restoration of the monument (Vourdounario \& Workmen's house).

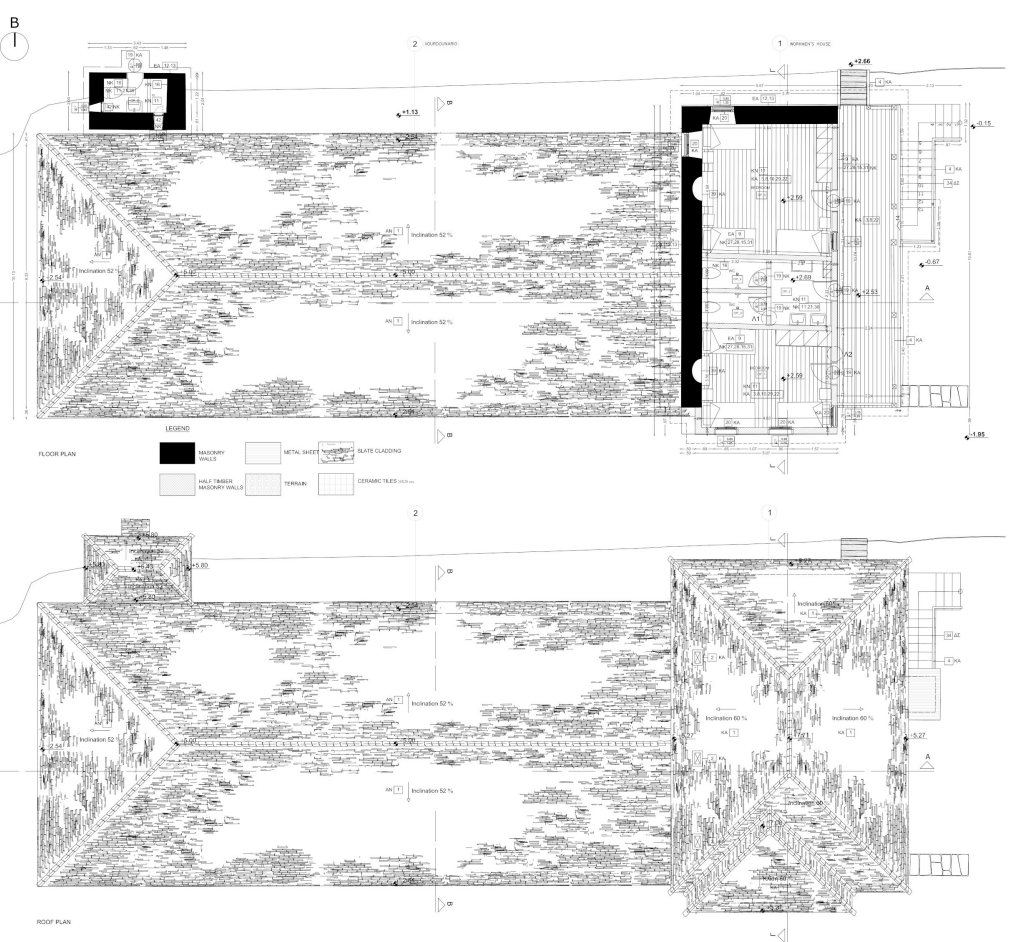

Figure 15. First floor and roof plan of the proposal for the restoration of the monument (Vourdounario \& Workmen's house). 


\section{Structural Analysis of the Monument and Discussion}

The structure was simulated using finite elements and was studied as a continuous structure formed by two parts: the "vourdounario", and the workmen's house, sharing a wall with an opening which allows the access between the two distinct areas (Figure 16). Although the Equivalent Frame Modelling of masonry structures is acknowledged as ideal for the analysis of such structures [7,8], or even discrete element analysis [9], the structural analysis software employed for the present work was SAP2000 nonlinear by CSI [10].
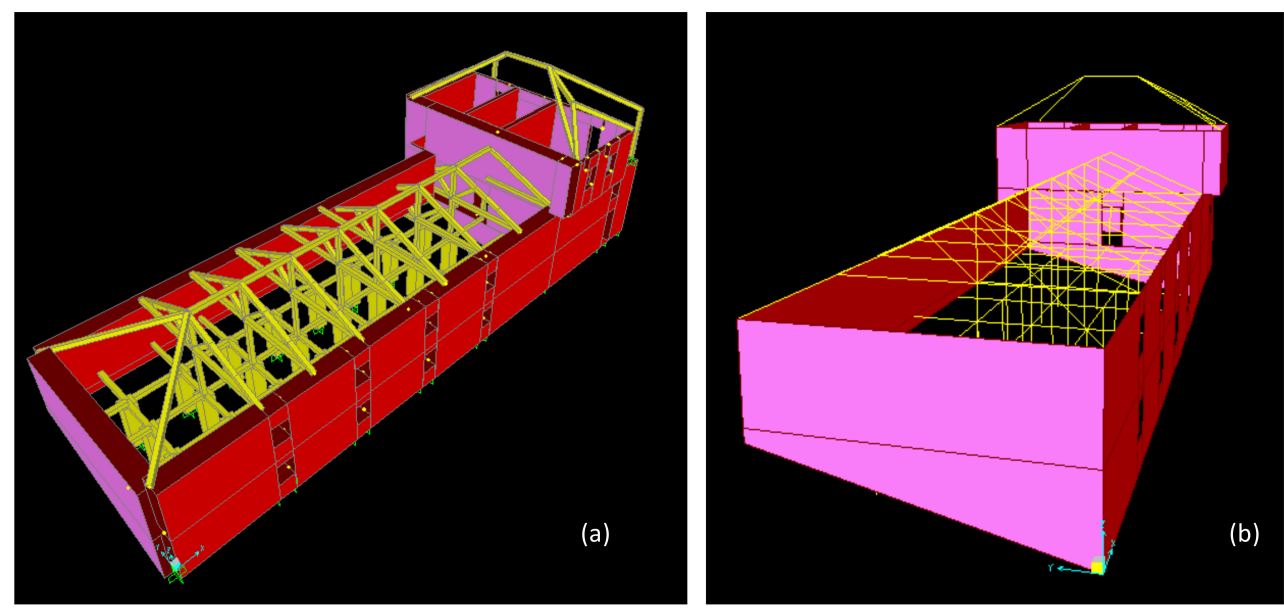

Figure 16. Geometric layout of the finite element model: (a) general layout, (b) different height of foundations.

\subsection{Description of the Structural Model}

The walls were modelled using quadrilateral shell elements. Two different section properties were defined: (i) one with a thickness of $0.75 \mathrm{~m}$ (mostly belonging to the "vourdounario" and the ground floor of the workmen's house), and (ii) walls with a thickness of $0.25 \mathrm{~m}$ belonging to the first floor of the workmen's house (the front wall and all partition walls).

The actual mechanical properties of the masonry were derived for both types of walls by the empirical formulae. It should be noted that the thickness of the walls varied with their heights. In fact, at their bases, the walls had a thickness of $103 \mathrm{~cm}$, whereas at their tops a thickness of $73 \mathrm{~cm}$ was recorded. A reduced average thickness equal to $0.75 \mathrm{~m}$ was used for the simulations of the restored model.

The masonry pillar footings were $0.60 \times 0.60 \mathrm{~m}$ cross sections but of different heights, due to the ground inclination. The exact location of the pillars assigned to the model were taken by a through surveying plot. The mechanical properties were assigned as per the walls.

The timber roofs were modelled using linear elements, which formed plain frames at specific distances forming the 3-dimensional timber structure. Two different 3-D roof structures were modelled: one for the "vourdounario" and the other for the workmen's house. Primary beams were $0.15 \times 0.15 \mathrm{~m}$ and the secondary beams were $0.05 \times 0.05 \mathrm{~m}$. The timber triangular frames were simply supported on the side walls, while at midspan they were connected with a timber column. All timber columns transfer the loads to the underlying mid-line masonry pillar footings which were perfectly aligned.

The floors were comprised of beams at specific spaces for the "vourdounario", whereas for the workmen's house, the floors were modelled as a diaphragm with shell elements with the equivalent thickness, due to different construction conditions.

The boundary condition for the building was considered as fixed to the ground (Figure 16). 
Lateral force (LFX in the $X$ direction and LFY in the $Y$ direction) and response spectrum seismic (RFX in the $X$ direction and RFY in the $Y$ direction) analyses were performed in both directions and compared.

It should be noted that typically for lateral force analysis, the software applies calculations on the first mode shape. However, in the case of this structure, the first mode shape marginally activated the timber beams of the roof. Therefore, instead of allowing the software to run the lateral force analysis using the first mode shape, the total mass was calculated using the seismic design response spectrum $\left(\Phi_{d(T)}\right)$, and equivalent forces were applied manually along the walls of the structure.

In fact, using the EC8 seismic code [11], for the plateau of the pseudo-acceleration spectrum:

$$
S_{d}=\frac{a_{g} \cdot s \cdot 2.5}{q}=0.62 \mathrm{~g}
$$

where $\gamma_{I}=1.30$ (EC8, Paragraph 2.1-for category 4);

$a_{g R}=0.24 \mathrm{~g}(\mathrm{EC} 8$, National annex for Greece, Paragraph 3.2.1, Table 1, for the Athos Peninsula); $a_{g}=a_{g R} \gamma_{I}=0.312 \mathrm{~g}$;

$q=1.5$ (Assumption of the authors);

$S=1.2$ For soil category B.

$$
V_{0}=M \cdot S_{d}
$$

The axial force of the seismic combination is computed as follows taking into consideration dead and live loads as $G=126.09 \mathrm{kN} / \mathrm{m}$ and $Q=5.30 \mathrm{kN} / \mathrm{m}$ :

$$
N_{s d, \tau \iota \chi}=1.00 G+0.80 Q=1.00 \times 126.09+0.80 \times 5.30=130.33 \mathrm{kN} / \mathrm{m}
$$

The total mass of the structure is equal to:

$$
M=\frac{N_{s d} \cdot l_{t o t}}{\mathrm{~g}}=\frac{130.33 \times(22.3+8.3) \times 2}{\mathrm{~g}}=\frac{7976.2}{\mathrm{~g}} \mathrm{kN},
$$

Therefore:

$$
(2)=>V_{0}=\frac{7976.2}{\mathrm{~g}} \times 0.62 \mathrm{~g}=4945.24 \mathrm{kN}
$$

\subsection{Simplifying Calculations}

Given the time required to create a finite element model, the following simplifying calculations were made in order to check the results with the ones given by the FEA. Moreover, given the irregularities discussed with respect to the height of the masonry pillar footings, it is well expected that stresses will be increased. In order to account for that, two unfavorable characteristics have been considered: (i) the increase of section forces, and (ii) the reduction of the strengths of materials.

This was achieved by:

1. Selecting the horizontal section of the spectrum as discussed above;

2. Modelling walls as cantilevers; therefore, imposing greater bending moments than in the actual structure;

3. Doubling the shear force carried by the wall;

4. Reducing the compressive strength of the stone comprising the masonry walls.

The following simplifying considerations were made: (i) the walls forming the plan of the vourdounario are of dimensions $23.3 \times 9.3 \mathrm{~m}$, with a cross section of $b_{v} \times h_{v}=1.0 \times 8.3 \mathrm{~m}$; (ii) the longitudinal wall with a length of $23.3 \mathrm{~m}$ will be checked for seismic excitation in the $y$-direction (Figure 17), which is the most unfavorable; (iii) the seismic combination which is considered is $1.00 G+0.80 Q \pm E$, because it creates the highest bending moment at the transverse walls. 


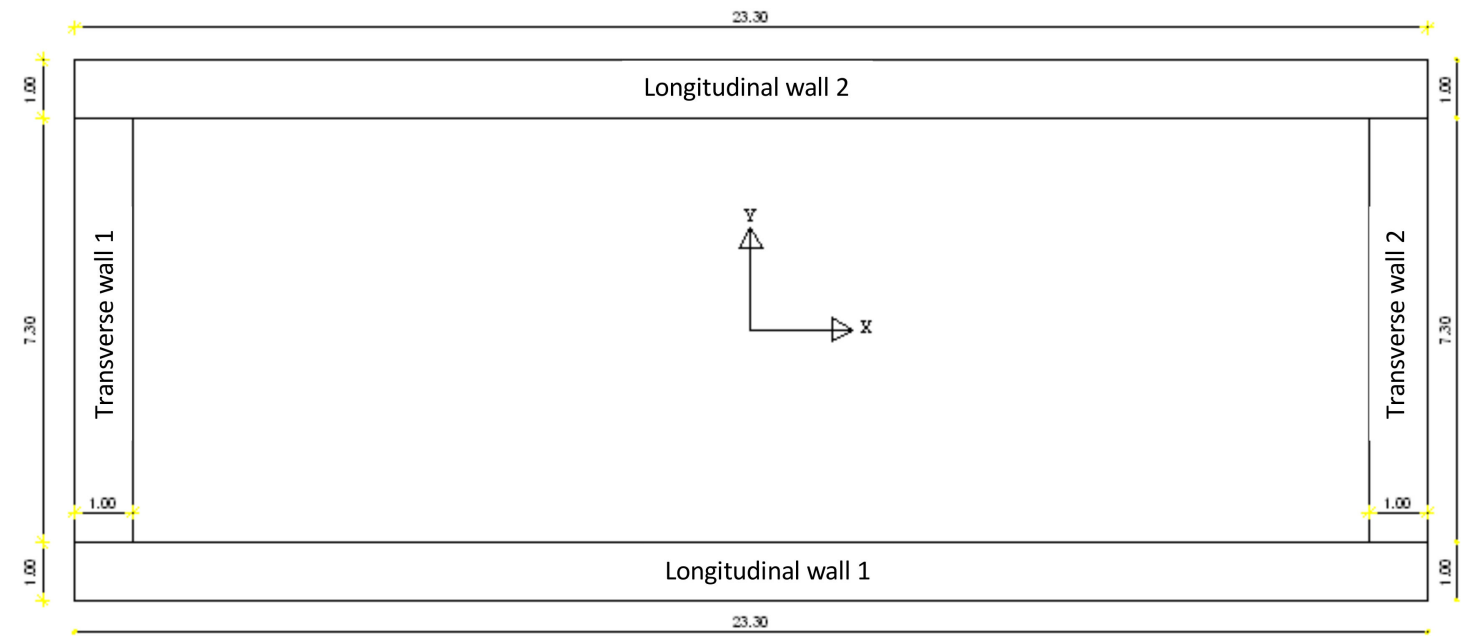

Figure 17. Simplified model of the walls of the vourdounario.

The shear force at the base of the wall in each direction $x$ and $y$ is related to the stiffness of the wall over the overall stiffness of the structure, where:

$$
\sum K_{\text {structure }}=2 * K_{\text {wall }, x, y}
$$

where

$K_{\text {wall }, x, y}=k_{i}$.

It is known that:

$$
k_{i}=\frac{3 E I G A_{w}}{h\left(h^{2} G A_{w}+3 E I\right)}
$$

E: Modulus of elasticity, $1200 \mathrm{MPa}$;

$G$ : shear modulus, $400 \mathrm{MPa}$;

I: moment of inertia of the wall;

$A$ : the area of the wall;

$h$ : height of the wall, $3 \mathrm{~m}$;

Dimensions of the wall in $x$ direction, $22.3 \mathrm{~m} \times 0.75 \mathrm{~m}$;

Dimensions of the wall in $y$ direction, $8.3 \mathrm{~m} \times 0.75 \mathrm{~m}$;

Replacing the above values:

$K x=1,941,748 \mathrm{kN} / \mathrm{m}$;

$\mathrm{Ky}=706,869 \mathrm{kN} / \mathrm{m}$;

$K_{\text {structure } x}=2 K x=3,883,495 \mathrm{kN} / \mathrm{m}$;

$K_{\text {structure } y}=2 K y=1,413,738 \mathrm{kN} / \mathrm{m}$.

From (4):

$$
\begin{gathered}
(4)=>V_{0}=4945.24 \mathrm{kN} \\
V_{s d, w a l l}=V_{0} / \rho x l_{\text {wall }, x}=110.8 \mathrm{kN} / \mathrm{m}
\end{gathered}
$$

The design bending moment can then be calculated for a $5 \mathrm{~m}$ cantilever:

$$
M_{s d, \text { wall }}=(2 / 3) \cdot V_{\text {sd,wall }} \cdot h_{\text {wall }}=(2 / 3) \times 110.8 \times 3.00=221.8 \mathrm{kNm}
$$

However, since this type of structure does not conform to the Eurocodes, because in old structures stone and mortar are not specified, it is preferred to use literature sources giving compressive and shear strengths according to the mortar and masonry characteristics [12].

The characteristic compressive strength of the masonry, $f_{k}$ was equal to $2.1 \mathrm{MPa}$ [12]. 
Regarding the shear strength

$$
f_{v k}=f_{v k 0}+0.40 \cdot \sigma_{d}
$$

where:

$f_{v k 0}$ : is the characteristic initial shear strength, under zero compressive stress [12];

$\sigma_{d}$ : is the design compressive stress perpendicular to the shear in the member at the level under consideration, using the appropriate load combination based on the average vertical stress over the compressed part of the wall that is providing shear resistance;

From literature review [12], $f_{v k 0}=0.20 \mathrm{~N} / \mathrm{mm}^{2}(\mathrm{MPa})$;

Moreover: $\sigma_{d}=N_{s d} / A_{\text {wall }, H O R}=130.33 /(1.00 \times 0.75)=173.8 \times 10^{-3} \mathrm{MPa}$.

Therefore,

$$
f_{v k}=0.20+0.40 \times 173.8 \times 10^{-3}=0.27 \mathrm{MPa}
$$

Simplifying calculations for the structure subjected to vertical loading, shear loading, and lateral loading have also been carried out, but lie beyond the scope of the current paper and are therefore not shown.

\subsection{FEA Model Results and Discussion}

With respect to the response spectrum analysis, it is worth noting that 300 mode shapes had to be considered in order to satisfy the EC 8 rule, which states that the number of mode shapes should be enough in order to excite at least $90 \%$ of the total mass. Figure 18 shows the main translational eigen modes at different periods $(\mathrm{T})$.

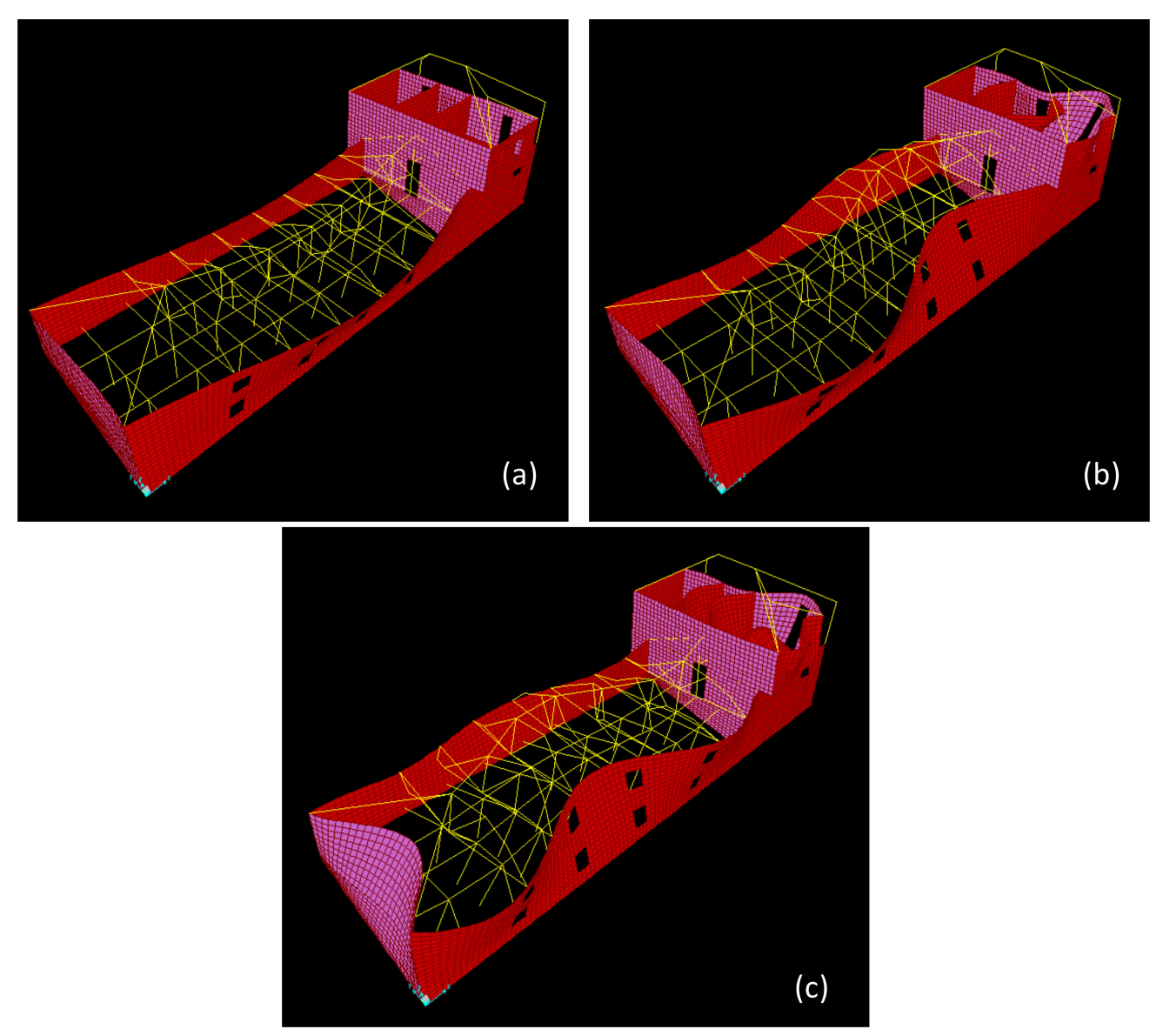

Figure 18. Eigen modes of the finite element model (a) Mode 15 th $\mathrm{T}=0.069 \mathrm{~s}$., (b) Mode 17th T $=0.059$ s., and (c) Mode 29th T $=0.048$ s. 


\subsubsection{Displacements}

Figure 19 shows maximum displacements at specific joints. The maximum displacement for excitation at both directions for seismic action ( $X$ and $Y$ ) have been calculated for both lateral force analysis (LFX and LFY) and response spectrum analysis (RSX and RSY).

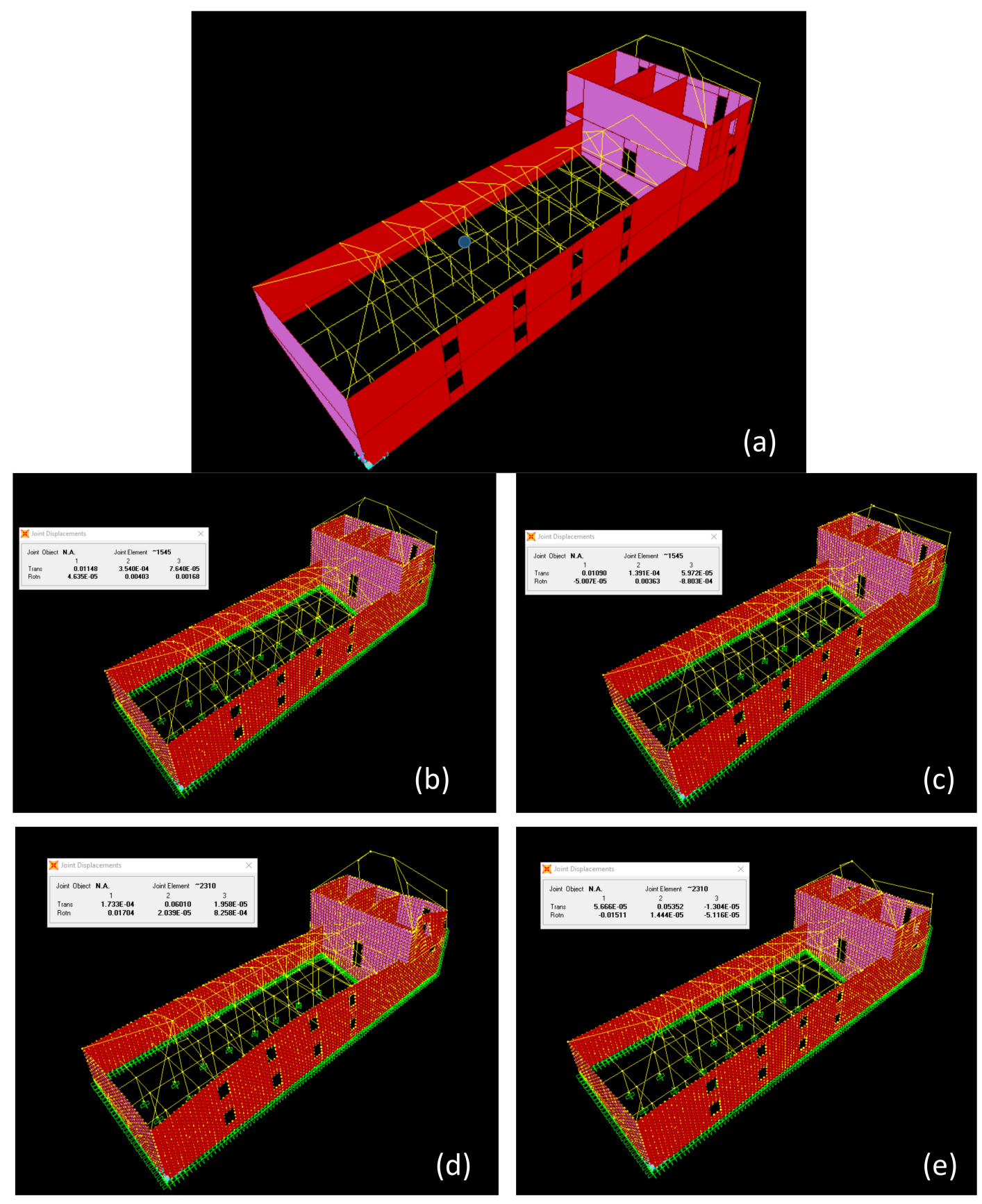

Figure 19. Displacement results of the finite element model (a) position of the node were values are recorded, (b) RSX, (c) LFX, (d) RSY and (e) LFY.

For the response spectrum analysis, the maximum displacement recorded for the RSY excitation was $6.01 \mathrm{~cm}$ in the middle of the south wall of the "vourdounario". Due to the section irregularity, the workmen's house undergoes the highest displacements and the greatest stress, as will be shown in the next paragraph. The maximum displacement recorded for the RSX excitation was $1.14 \mathrm{~cm}$ in the middle of the west wall of the "vourdounario". 
For the lateral force analysis, the maximum displacement recorded for the LFY excitation was $5.35 \mathrm{~cm}$ in the middle of the south wall of the "vourdounario". Due to the section irregularity, the workmen's house undergoes the highest displacements and the greatest stress, as will be shown in the next paragraph. The maximum displacement recorded for the LFX excitation was $1.09 \mathrm{~cm}$ in the middle of the west wall of the "vourdounario".

\subsubsection{Stresses}

Figure 20 shows the normal (Stress 11 and Stress 22) and shear stress (Stress 12) distribution in the structure. Maximum normal compressive stress calculated by the analysis does not exceed the masonry stress capacity, which is $2.1 \mathrm{MPa}$. The stresses were calculated for seismic action in the $x$ direction (RSX) and for seismic action in the $y$ direction (RSY). The following loading combinations for accidental (earthquake RSX \& RSY for response spectrum analysis or LFX \& LFY for lateral force analysis), permanent (G) and variable actions $(\mathrm{Q})$ have been considered (Table 1$)$.
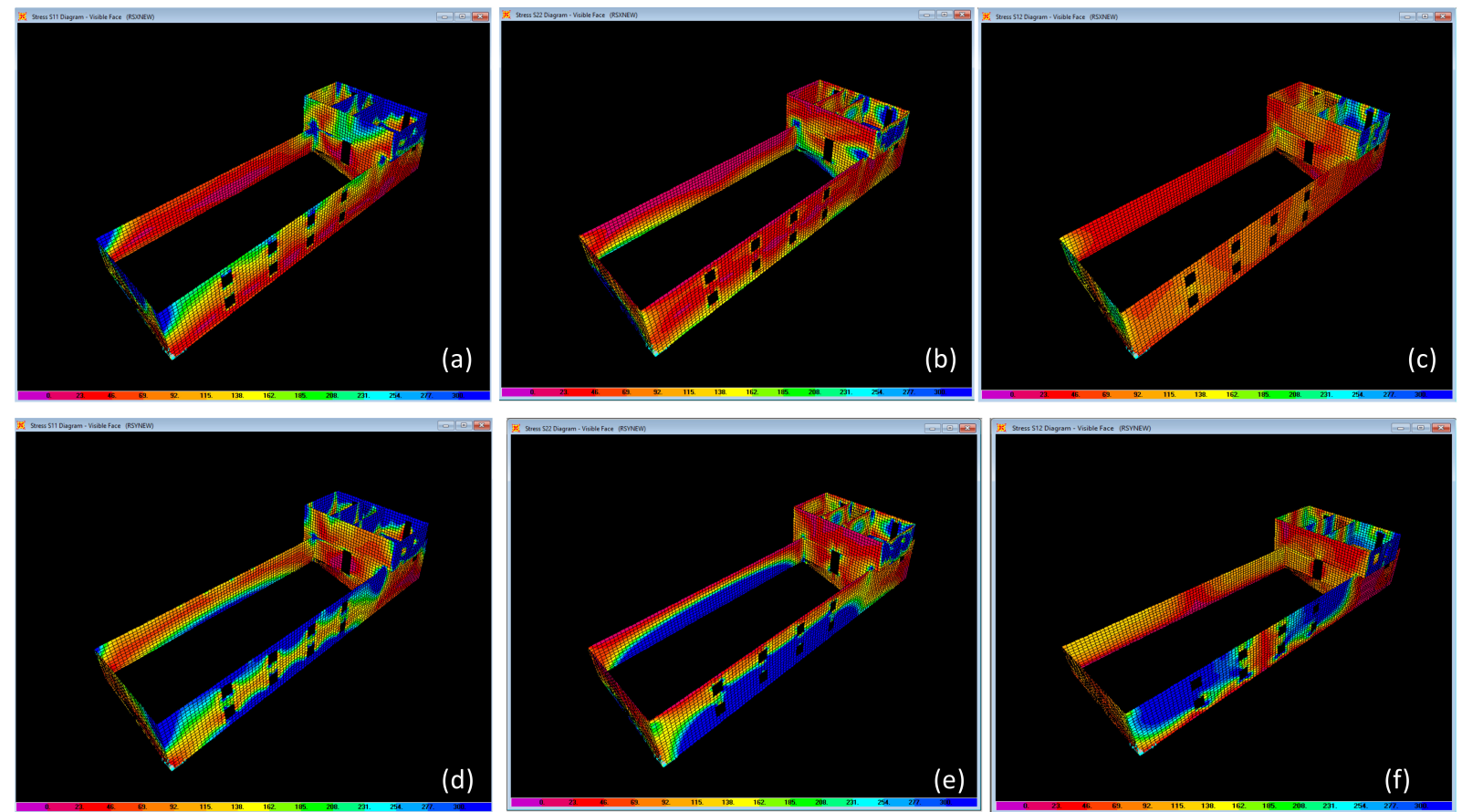

Figure 20. Stress results of the finite element model (a) Stress 11 RSX, (b) Stress 22 RSX, (c) Stress 12 RSX, (d) Stress 11 RSY, (e) Stress 22 RSY and (f) Stress 12 RSY.

Table 1. Loading combinations for the response spectrum analysis and for the lateral force analysis.

\begin{tabular}{cc}
\hline Response Spectrum Analysis & Lateral Force Analysis \\
\hline$G+0.3 Q+R S X+0.3 R S Y$ & $G+0.3 Q+L F X+0.3 L F Y$ \\
$G+0.3 Q+R S X-0.3 R S Y$ & $G+0.3 Q+L F X-0.3 L F Y$ \\
$G+0.3 Q-R S X+0.3 R S Y$ & $G+0.3 Q-L F X+0.3 L F Y$ \\
$G+0.3 Q-R S X-0.3 R S Y$ & $G+0.3 Q-L F X-0.3 L F Y$ \\
$G+0.3 Q+0.3 R S X+R S Y$ & $G+0.3 Q+0.3 L F X+L F Y$ \\
$G+0.3 Q+0.3 R S X-R S Y$ & $G+0.3 Q+0.3 L F X-L F Y$ \\
$G+0.3 Q-0.3 R S X+R S Y$ & $G+0.3 Q-0.3 L F X+L F Y$ \\
$G+0.3 Q-0.3 R S X-R S Y$ & $G+0.3 Q-0.3 L F X-L F Y$ \\
\hline
\end{tabular}

Maximum stresses are identified by blue color. Again, due to the section irregularity, the workmen's house undergoes the greatest stress, as discussed previously with respect to displacements. The same goes for all corners of the "vourdounario" which are the most 
vulnerable. The displacement and stress results of the restored structure are summarized in Table 2.

Table 2. Comparison of displacement and stress results of the restored structure.

\begin{tabular}{|c|c|c|c|c|}
\hline & \multicolumn{2}{|c|}{$\begin{array}{l}\text { Displacement } \\
\text { (cm) }\end{array}$} & \multirow{2}{*}{$\begin{array}{c}\text { Max Normal } \\
\text { Stress S11 } \\
\text { (MPa) }\end{array}$} & \multirow{2}{*}{$\begin{array}{c}\text { Max Shear } \\
\text { Stress S12 } \\
\text { (MPa) }\end{array}$} \\
\hline & $X$ Direction & $Y$ Direction & & \\
\hline $\begin{array}{l}\text { Restored } \\
\text { structure }\end{array}$ & 1.14 & 6.01 & 1.856 & 0.187 \\
\hline
\end{tabular}

It is well known that, with finite element modelling, a better picture of the stress and deformation environment due to loading is produced. However, in many cases of masonry structures, the local failure mechanisms are proven more critical [12]. These local mechanisms cannot be detected by finite element modelling software and will be the subject of future investigation so that both analyses will be compared.

\section{Conclusions}

In the present study, an extinct type of UNESCO monument has been presented in terms of historical and typological characteristics. A set of architectural drawings provides the exact description of the monument at its present state, while another set of architectural drawings presents the restoration proposal, which was accepted by CAC. The current pathology of the monument has been described in depth and a set of simplifying calculations for the load bearing capacity of the structure has been provided. Then, a numerical finite element analysis model was designed to evaluate the displacements and consequently the stresses which are developed in the structure under various loading combinations. It was found that the elaborate analytical model yielded stresses which did not exceed the bearing capacity calculated using the simplified procedure. Therefore, this procedure, even in irregular monuments, can yield acceptable results if the time and resources are not sufficient for the development of a finite element model. In fact, the two different approaches indicate that the proposed design is effective in improving the earthquake performance of the structure.

Author Contributions: Conceptualization and methodology, S.P.; historical data and pathology, K.D. and G.M.; surveying plots and architectural drawings, G.S. and V.F.; Discussion of architectural proposal, G.M.; structural analysis and discussion, S.P. and N.P.; writing-original draft preparation, S.P.; writing-review and editing, S.P., G.M. and N.P. All authors have read and agreed to the published version of the manuscript.

Funding: This research received no external funding.

Acknowledgments: The authors acknowledge the contribution of the following architects for the production of the drawings: Ioannis Vasiliades, Christos Leras, Georgios Bougiouklis, Georgios Mavrides, and civil engineer Vera Galanidou.

Conflicts of Interest: The authors declare no conflict of interest.

\section{References}

1. Rodwell, D. The Unesco World Heritage Convention, 1972-2012: Reflections and Directions. Hist. Environ. Policy Pract. 2012, 3 , 64-85. [CrossRef]

2. Della Dora, V. Setting and Blurring Boundaries: Pilgrims, Tourists, and Landscape in Mount Athos and Meteora. Ann. Tour. Res. 2012, 39, 951-974. [CrossRef]

3. Woodhouse, C. The Greek War of Independence: Its Historical Setting, 1st ed.; Hutchinson's University Library: New York, NY, USA, 1952.

4. Paschalides, S. A Pilgrim's Guide; The Holy Monastery of Pantokrator: Mount Athos, Greece, 2005. (In Greek)

5. Goe, M.; Alldredge, J.; Light, D. Use of heart girth to predict body weight of working oxen in the Ethiopian highlands. Livest. Prod. Sci. 2001, 69, 187-195. [CrossRef] 
6. International Council on Monuments and Sites (ICOMOS). International Charter for the Conservation and Restoration of Monuments and Sites: The Venice Charter; ICOMOS: Paris, France, 1964.

7. Formisano, A.; Florio, G.; Landolfo, R.; Mazzolani, F.M. Numerical calibration of an easy method for seismic behaviour assessment on large scale of masonry building aggregates. Adv. Eng. Softw. 2015, 80, 116-138. [CrossRef]

8. Lagomarsino, S.; Penna, A.; Galasco, A.; Cattari, S. TREMURI program: An equivalent frame model for the nonlinear seismic analysis of masonry buildings. Eng. Struct. 2013, 56, 1787-1799. [CrossRef]

9. Pantò, B.; Cannizzaro, F.; Caddemi, S.; Caliò, I. 3D macro-element modelling approach for seismic assessment of historical masonry churches. Adv. Eng. Softw. 2016, 97, 40-59. [CrossRef]

10. Computers and Structures, Inc. SAP2000®v.14: Three Dimensional Static and Dynamic Finite Element Analysis and Design of Structures; Computers and Structures, Inc.: Berkeley, CA, USA, 2007.

11. Earthquake Planning and Protection Organization (EPPO). National Greek Seismic Code; EPPO: Athens, Greece, 2001.

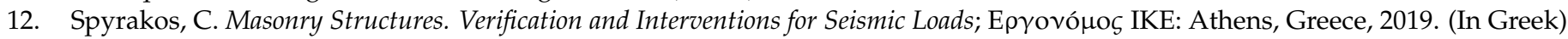

